\title{
Bacterial Ohr and OsmC paralogues define two protein families with distinct functions and patterns of expression
}

\author{
Sopapan Atichartpongkul, ${ }^{1}$ Suvit Loprasert, ${ }^{1}$ Paiboon Vattanaviboon, ${ }^{1}$ \\ Wirongrong Whangsuk, ${ }^{1}$ John D. Helmann ${ }^{3}$ and Skorn Mongkolsuk ${ }^{1,2}$
}

\footnotetext{
1 Laboratory of Biotechnology, Chulabhorn Research Institute, Lak Si, Bangkok 10210, Thailand

2 Department of Biotechnology, Faculty of Science, Mahidol University, Bangkok 10400, Thailand

3 Department of Microbiology, Wing Hall, Cornell University, Ithaca, NY 14853-8101, USA
}

\author{
Author for correspondence: Skorn Mongkolsuk. Tel: +6625740623 ext. 1402. Fax: +6625742027. \\ e-mail: skorn@tubtim.cri.or.th
}

\begin{abstract}
Xanthomonas campestris Ohr (a protein involved in organic peroxide protection) and Escherichia coli OsmC (an osmotically inducible protein of unknown function) are related proteins. Database searches and phylogenetic analyses reveal that $\mathrm{Ohr}$ and OsmC homologues cluster into two related subfamilies of proteins widely distributed in both Gram-negative and Grampositive bacteria. To determine if these two subfamilies are functionally distinct, ohr and osmC in Pseudomonas aeruginosa (a bacterium with one representative from each subfamily) were analysed. Only ohr mutants are hypersensitive to organic peroxide, and this phenotype can be restored by complementation with ohr but not osmC. In addition, expression of ohr was highly induced only by organic peroxides, and not by other oxidants or stresses. In contrast, osmC was induced by ethanol and osmotic stress. A similar pattern of regulation was observed for Ohr and OsmC homologues in the Gram-positive bacterium Deinococcus radiodurans, though uninduced expression was much higher and induction lower in this species. These data clearly support the conclusion that $\mathrm{Ohr}$ and OsmC define two functionally distinct subfamilies with distinct patterns of regulation.
\end{abstract}

Keywords: Pseudomonas aeruginosa, Deinococcus radiodurans, organic peroxide resistance, osmotic stress

\section{INTRODUCTION}

Organic peroxides are highly toxic and can damage cellular macromolecules, including proteins, lipids and DNA. Furthermore, these compounds participate in free-radical reactions that generate more reactive organic radicals which thereby increases their toxicity (Halliwell \& Gutteridge, 1984). In bacteria, organic peroxides are generated as by-products of aerobic metabolism (Gonzales-Flecha \& Demple, 1997). In addition, pathogenic bacteria are exposed to reactive oxygen species, including organic peroxides, generated by the host as a part of the active defence response (Baker \& Orlandi, 1995; Levine et al., 1994). Thus, detoxification of organic peroxides is important for bacterial survival and proliferation in the host.

Abbreviations: Ahp, alkyl hydroperoxide reductase; $\mathrm{tBOOH}$, tert-butyl hydroperoxide.
Bacteria have evolved complex systems to protect themselves from organic-peroxide toxicity. Alkyl hydroperoxide reductase (Ahp) is the best-characterized bacterial enzyme involved in the metabolism of organic peroxides (Poole, 1996; Niimura et al., 1995). This enzyme consists of two subunits: catalytic subunit $\mathrm{C}$ $(\mathrm{AhpC})$ and reductase subunit $\mathrm{F}(\mathrm{AhpF})$. AhpC reduces organic peroxides to the corresponding alcohols (Poole \& Ellis, 1996). AhpC belongs to a large family of peroxidases (the AhpC/thiol-specific antioxidant family) found in organisms ranging from bacteria to man (Chae et al., 1994a). Some organisms express multiple $\mathrm{AhpC} /$ thiol-specific antioxidant paralogues, presumably with distinct functions (regulation or cellular localization) (Baillon et al., 1999; Bsat et al., 1996; Hillas et al., 2000).

In the bacterial phytopathogen Xanthomonas campestris pv. phaseoli, the defence against organicperoxide toxicity is complex (Loprasert et al., 1996). In addition to $\mathrm{AhpC}$, there is a recently characterized novel 
organic hydroperoxide resistance gene, ohr (Loprasert et al., 1997; Mongkolsuk et al., 1998a). X. campestris ohr mutants are sensitive to organic peroxides, but not to other oxidants (Mongkolsuk et al., 1998a). In addition, ohr has a unique pattern of oxidant-induced expression; only organic peroxides induce high levels of expression (Mongkolsuk et al., 1998a). This unusual pattern of induction distinguishes $\mathrm{obr}$ from other known oxidative stress genes. Analysis of Ohr primary structure shows that it has homology to proteins with unknown functions from both Gram-positive and Gram-negative bacteria, and that it has moderate homology to an osmotically inducible protein (OsmC) from Escherichia coli (Gutierrez \& Devedjian, 1991).

On the basis of sequence analysis of Ohr and OsmC homologues, we propose that these two proteins define two protein subfamilies. In this report, we focus on two organisms with one member of each subfamily: Pseudomonas aeruginosa and Deinococcus radiodurans. Genetic analyses in $P$. aeruginosa, and expression studies in both organisms, support the hypothesis that these proteins are functionally, as well as structurally, distinct.

\section{METHODS}

Bacterial strains, growth conditions and oxidant killing. Xanthomonas strains, $D$. radiodurans and $P$. aeruginosa PAO1 were grown in Silva-Buddenhagen medium $(0.5 \%$ sucrose, $0.5 \%$ yeast extract, $0.5 \%$ peptone, $0.1 \%$ glutamic acid; pH 7.0) at $28{ }^{\circ} \mathrm{C}$, TGY medium $(0 \cdot 1 \%$ glucose, $0 \cdot 8 \%$ tryptone, $0.4 \%$ yeast extract; $\mathrm{pH} 7 \cdot 2)$ at $32{ }^{\circ} \mathrm{C}$ and LuriaBertani (LB) medium at $37^{\circ} \mathrm{C}$, respectively. Bacterial growth was monitored spectrophotometrically at $\mathrm{OD}_{600}$.

Quantitative determinations of plating efficiency in the presence of various oxidants of Pseudomonas strains were performed as described previously (Hassett et al., 2000; Ochsner et al., 2000). Essentially, cells from exponential phase cultures were serially diluted and plated on LB agar containing various concentrations of tert-butyl hydroperoxide $(\mathrm{tBOOH})$. The numbers of colonies at the different oxidant concentrations were counted after $24 \mathrm{~h}$ incubation at $37^{\circ} \mathrm{C}$. Percentage survival is defined as the percentage ratio between the c.f.u. growing on plates containing $\mathrm{tBOOH}$ and those growing on plates without $\mathrm{tBOOH}$.

Alignment and phylogenetic analysis. Protein sequences related to $\mathrm{Ohr}$ and $\mathrm{OsmC}$ were retrieved from public sequence databases using the BLAST program (Altschul et al., 1997). These amino acid sequences were aligned using the program Clustal w, version 1.7 (Thompson et al., 1994). A phylogenetic tree was constructed by the neighbour-joining method, using the TREE program from the phylogenetic analysis page of D. L. Robertson, E. Beaudoing \& J. M. Claverie (http://igsserver.cnrss-mrs.fr/anrs/phylogenetics). The results were drawn using the program PHYLODENDRON, version 0.8d (D. G. Gilbert, Department of Biology, University of Indiana, USA; http://iubio.bio.indiana.edu).

Stress-induced expression of ohr and osmC. Exponential phase cultures $\left(\mathrm{OD}_{600}=0 \cdot 4\right)$ were divided into flasks and oxidants or other chemicals were added. The following concentrations of chemicals were used : $250 \mu \mathrm{M} \mathrm{H}_{2} \mathrm{O}_{2}, 200 \mu \mathrm{M}$ cumene hydroperoxide, $200 \mu \mathrm{M} \mathrm{tBOOH}, 100 \mu \mathrm{M}$ menadione, $2 \%(\mathrm{w} / \mathrm{v})$ sodium chloride and $4 \%(\mathrm{v} / \mathrm{v})$ ethanol for $P$. aeruginosa; $250 \mu \mathrm{M} \mathrm{H} \mathrm{H}_{2} \mathrm{O}_{2}, 100 \mu \mathrm{M}$ tBOOH, $4 \%$ (w/v) sodium chloride and $4 \%(\mathrm{v} / \mathrm{v})$ ethanol for D. radiodurans. Treated and untreated cultures were harvested after $20 \mathrm{~min}$ incubation at appropriate temperatures.

Cloning of $\boldsymbol{P}$. aeruginosa ohr and osmC. Full-length $P$. aeruginosa ohr and osm $\mathrm{C}$ genes were cloned using PCR. Primers 5' ohrP (5'-TCAGACAGGTGACTCTC-3'), 3'ohrP (5'-AGTCGGAAGCTTCAGAC-3'), 5'osmCP (5'-CGACGCGAGCGGATGTC-3') and 3'osmCP (5'-AGCGTTCCGCTCAGCCG $3^{\prime}$ ) were designed using sequence data obtained from the genome sequence of $P$. aeruginosa (Stover et al., 2000). A primer pair, P. aeruginosa genomic DNA, the PCR reaction mix and $2 \mathrm{U} P f u$ polymerase were mixed and used to amplify either ohr or osmC genes, under the following conditions: denaturation at $96^{\circ} \mathrm{C}$ for $1 \mathrm{~min}$, annealing at $50{ }^{\circ} \mathrm{C}$ for $1 \mathrm{~min}$, and extension at $72{ }^{\circ} \mathrm{C}$ for $2 \mathrm{~min}$. The $450 \mathrm{bp}$ $o h r$ and $470 \mathrm{bp}$ osm C PCR-generated fragments were cloned into pBBR1MCS-4 and pBBR1MCS-5, respectively (Kovach et al., 1994), giving two recombinant plasmids, pBBRohrP and pBBRosmCP. The nucleotide sequences of both genes were determined using a BigDye terminator cycle sequencing kit on an automated DNA sequencer (ABI 310).

Construction of ohr and osmC mutants in $P$. aeruginosa. Mutants were constructed by insertional inactivation of $o h r$ and $o s m C$ genes. Essentially, pBBRohrP was digested with Sfi and SacII. The ends of the $340 \mathrm{bp}$ fragment containing the coding region of $o h r$ were gap-filled by DNA polymerase, and the blunt-ended fragment was cloned into SmaI-digested pKnock-GM (Alexeyev, 1999) to give pKnock-ohr. Similarly, pBBRosmCP was digested with SalI and BstEII. The ends of the $240 \mathrm{bp}$ DNA fragment containing part of the osm $\mathrm{C}$ coding region were gap-filled by DNA polymerase, and cloned into SmaI-digested pKnock-Ap (Alexeyev, 1999) to give pKnockosmCP. The sequences of the cloned DNA in both recombinant plasmids were determined using an automated DNA sequencer (ABI 310). pKnock-ohrP and pKnock-osmCP were conjugated into $P$. aeruginosa PAOI as described previously (Hassett et al., 2000). Gentamicin-resistant and carbenicillinresistant colonies will arise from homologous recombination of the in-coming recombinant plasmid with either ohr or osm $\mathrm{C}$ genes on the chromosome, depending on the fragment on the plasmid. Insertion of the plasmid into the chromosome is expected to inactivate the gene. Transconjugants containing pKnock-ohr and $\mathrm{pKnock-osmC}$ were selected with gentamicin $\left(15 \mu \mathrm{g} \mathrm{ml}^{-1}\right)$ and carbenicillin $\left(200 \mu \mathrm{g} \mathrm{ml}^{-1}\right)$, respectively. Putative mutants were screened by PCR using a universal sequence primer for a site located in $\mathrm{pKnock}$ vectors and either the $3^{\prime} \mathrm{ohr}$ or the $3^{\prime} \mathrm{osmC}$ primer. The expected insertions resulting in inactivation of $o b r$ and $o s m C$ were confirmed by Southern analysis of genomic DNA extracted from the mutants and were probed with gene-specific probes (data not shown).

Northern analysis of ohr and osmC homologues. Total RNA was extracted from $P$. aeruginos $a$ and $D$. radiodurans by using the hot acid phenol method performed as described previously (Mongkolsuk et al., 1997). RNA samples were separated by electrophoresis in formaldehyde agarose gels and were then transferred by capillary action to pieces of nylon membrane. Total RNA $(10 \mu \mathrm{g})$ was loaded into each well. Probes were prepared, and RNA hybridization and membrane washing were performed as described previously (Mongkolsuk et al., 1997). P. aeruginosa ohr and osmC probes of $300 \mathrm{bp}$ and $375 \mathrm{bp}$, respectively, were made from $M l u \mathrm{I}$-digested pKnockohrP and Sfil-HindIII-digested pKnock-osmCP. The DNA fragments were separated on an agarose gel, extracted and then purified prior to being radioactively labelled using a 
random prime DNA-labelling kit. D. radiodurans ohr and osm $\mathrm{C}$ probes were made using PCR. Primers corresponding to coding regions of either ohr (5' ohrD, 5'-TGCGGGCGAGGGAATAG-3', and 3'ohrD, 5'-GTGTCTTATTCGCGGAC-3') or osmC (5' osmCD, 5' -CAGCGAGCACACTGGGC$3^{\prime}$, and $3^{\prime}$ osmCD, 5'-GCTTGAGCGACTCAGCC-3') were designed using the $D$. radiodurans genome sequence (White et al., 1999). PCR was performed with D. radiodurans genomic DNA and the gene-specific primers in the PCR reactions noted above, using the following conditions: denaturation at $96{ }^{\circ} \mathrm{C}$ for $1 \mathrm{~min}$, annealing at $50^{\circ} \mathrm{C}$ for $1 \mathrm{~min}$ and extension at $72{ }^{\circ} \mathrm{C}$ for $2 \mathrm{~min}$ for 35 cycles. The $445 \mathrm{bp}$ ohr and 470 bp osm C PCRgenerated fragments were gel-purified, and radioactively labelled probes were made using the random primer DNAlabelling kit.

\section{RESULTS AND DISCUSSION}

\section{Analysis of Ohr and OsmC homologues}

Analysis of Ohr homologues from various bacteria suggested that there were two groups of related proteins (Koonin et al., 2000; Mongkolsuk et al., 1998a; Volker et al., 1998). Some homologues, such as Ohr from Acinetobacter calcoaceticus and $P$. aeruginosa, have high levels of identity ( $50 \%$ or more), while others, such as E. coli OsmC, have moderate levels of identity (around 20\%) when compared with the Ohr from $X$. campestris pv. phaseoli (Mongkolsuk et al., 1998a). Since the physiological role of these homologues is unknown, it is not yet clear whether these structural distinctions are of functional significance. To address this question, we have performed a phylogenetic analysis of Ohr homologues and initiated molecular genetic studies in two model systems containing homologues from both the Ohr and the OsmC subfamilies.

X. campestris pv. phaseoli $\mathrm{Ohr}$ and E. coli OsmC amino acid sequences were used to search the GenBank and bacterial genome databases for related proteins. Homologues of both proteins are widely distributed in both Gram-negative and Gram-positive bacteria, but no homologues were detected in eukaryotes. Amino acid alignments generated using CLUSTAL $\mathrm{w}$ (Thompson et al., 1994) suggest that the Ohr/OsmC family can be divided into two subfamilies, each being defined by sequence motifs conserved only among Ohr (designated Oh regions) or only among OsmC (designated Os regions) homologues (Fig. 1). At present, we do not know the biological significance of these different motifs. A notable feature of the primary structure of $\mathrm{Ohr}$ and OsmC family members is the two highly conserved cysteine residues. $\mathrm{C}$ residues have been shown to be the active site of AhpC, an enzyme that metabolizes organic peroxide (Chae et al., 1994b). The amino acid sequences around the second $\mathrm{C}$ residue are conserved within members of the $\mathrm{Ohr}$ and OsmC families but are very diverse between the two families. The conserved amino acid region around C-125 of the Ohr family members contains the sequence motif VCPY (Fig. 1). This region is not present in members of the OsmC family. The VCPY motif places the cysteine residue in an environ- ment of abnormally strong nucleophilicity that makes it highly susceptible to reactive oxygen species (Lim et al., 1994). The strongly nucleophilic regions in thiol-specific antioxidant proteins such as AhpC (Chae et al., 1994b) and in the peroxide-scavenging protein ovothiol (Turner et al., 1988) have been shown to be the catalytic sites for the breakdown of peroxides. This suggests that the C125 residue in members of the Ohr family could participate in peroxide reduction. This idea is being investigated. The amino acid sequences were used to construct a phylogenetic tree (Fig. 2); it clearly shows that there are two separate groups of proteins, defined here as the $\mathrm{Ohr}$ and OsmC subfamilies.

Several bacteria produce either Ohr or OsmC. For example, Mycoplasma pneumoniae, Mycoplasma genitalium, Vibrio cholerae and Xylella fastidiosa have only the Ohr homologue, whereas E. coli has only an OsmC homologue. In Bacillus subtilis, Mycoplasma genitalium and Sinorhizobium meliloti, proteins described as 'OsmC homologues' (Volker et al., 1998) clearly belong to the Ohr subfamily (Fig. 2). Interestingly, Mycoplasma genitalium has no known proteins, other than the Ohr homologue, involved in peroxide detoxification (Fraser et al., 1995). This suggests that in some bacteria Ohr might have a crucial role (or roles) in protecting against peroxide toxicity. Neither Ohr nor OsmC homologues were found in the genomes of several bacteria such as Helicobacter pylori, Mycobacterium tuberculosis, Neisseria meningitidis and Rickettsia prowazekii. Overall, members of the $\mathrm{Ohr}$ family appear to be more widely distributed among diverse bacteria than members of the OsmC family.

Unexpectedly, several bacteria have homologues from both subfamilies. Several Gram-negative bacteria ( $P$. aeruginosa, Pseudomonas putida) and a Gram-positive bacterium (D. radiodurans) have one member each from the OsmC and Ohr subfamilies. Other Gram-positive bacteria, such as B. subtilis and Streptomyces coelicolor, have one member of the OsmC family and two or more members of the Ohr family. Multiple Ohr homologues have not been identified in genomes from Gram-negative bacteria. At present, the functions of the multiple $\mathrm{Ohr}$ homologues are unknown but are the subject of further investigation.

\section{Ohr and OsmC homologues have different physiological roles}

The separation of Ohr and OsmC homologues into two subfamilies raises an important question: do these two subfamilies have distinct or overlapping functions? Bacteria such as $P$. aeruginosa, having one member each from the $o h r$ and $o s m C$ subfamilies, offer an attractive model system for investigating this question. Using insertional inactivation, we generated mutants of the $P$. aeruginosa ohr and osm C genes. The P. aeruginosa ohr mutant, but not the osm $C$ mutant, has a much reduced (more than 100 times lower) plating efficiency on agar containing $500 \mu \mathrm{M}$ tBOOH when compared with the 

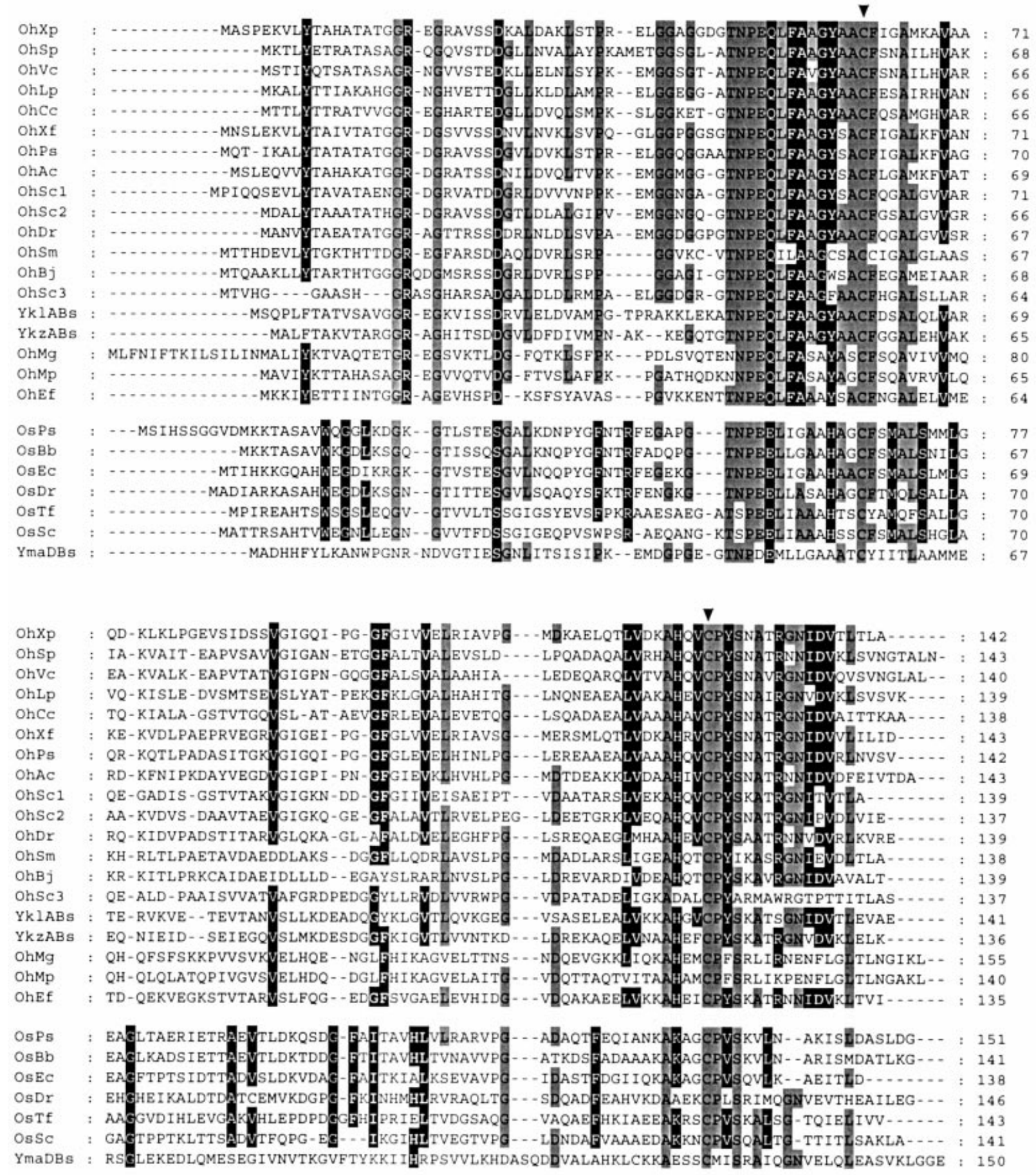

Fig. 1. Multiple amino acid sequence alignment of Ohr and OsmC homologues. Various homologues of Ohr and OsmC were aligned by using the CLUSTAL W program (Thompson et al., 1994). The origins of these proteins are as follows: OhXp is from Xanthomonas campestris pv. phaseoli (AF036166); OhSp is from Shewanella putrefaciens (TIGR24 sputre6401)*; OhVc is from Vibrio cholerae (AE003853); OhLp is from Legionella pneumophila (CUCGC446 Ipneumo WG.011079-R)*; OhCc is from Caulobacter crescentus (TIGR C.crescentus12574)*; OhXf is from Xylella fastidiosa (AE003849); OhPs is from Pseudomonas aeruginosa (PAGP 287 contig1)*; OhAc is from Acinetobacter (Y09102); OhSc1, OhSc2, OhSc3 and OsSc are from Streptomyces coelicolor (AL133423.1, AL163672.1, AL031515.1 and AL031515.1, respectively); OhDr and OsDr are from Deinococcus radiodurans (AE002025 and AE000513); OhSm is from Sinorhizobium meliloti (Stanford 382 smelil 423032c12)*; OhBj is from Bradyrhizobium japonicum (AAF78793.1); YklABs, YkzABs and YmaDBs are from Bacillus subtilis (AJ002571 and Z99113); OhMg is from Mycoplasma genitalium (U39732); OhMp is from Mycoplasma pneumoniae (MPAE00018); OhEf is from Enterococcus faecalis (TIGR1351 gef6391)*; OsPs is from P. aeruginosa (PAGP287 contig1)*; 


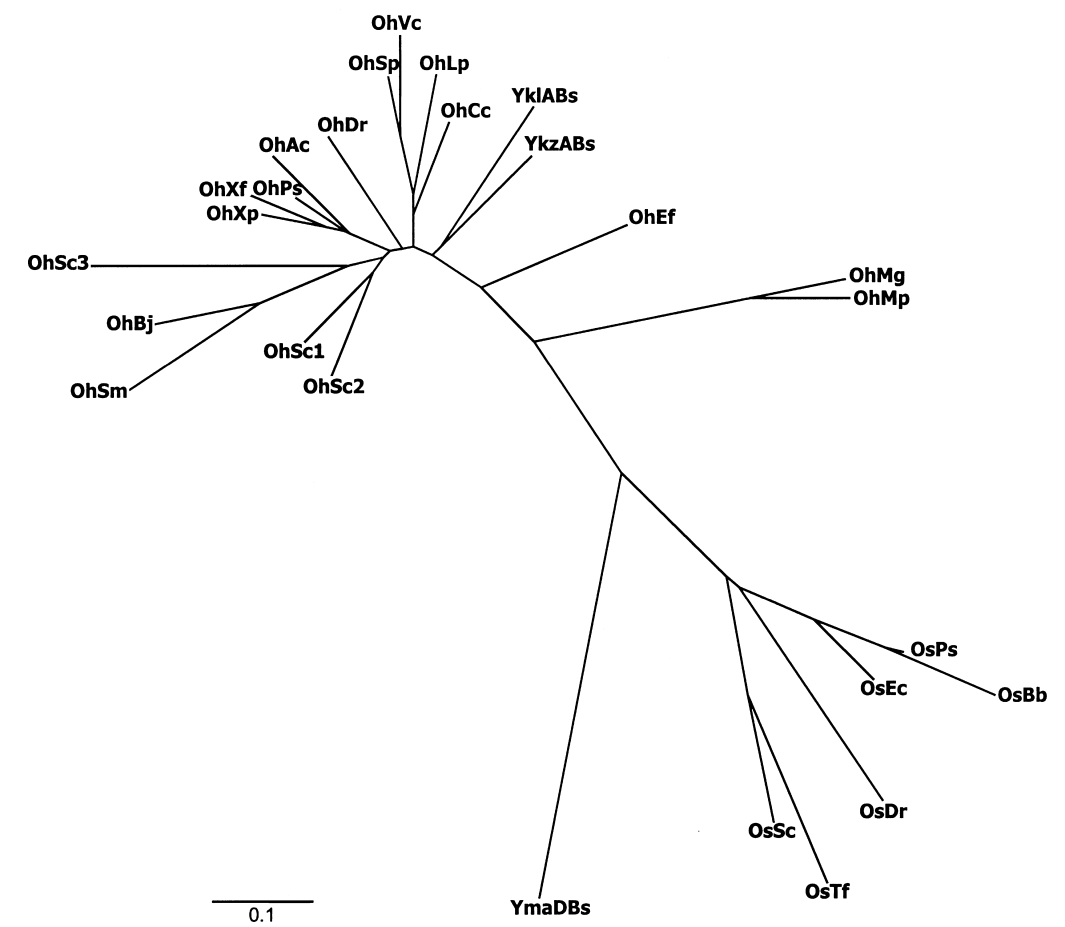

Fig. 2. An unrooted phylogenetic tree of Ohr and OsmC homologues. The tree was obtained by a neighbour-joining method by TREE phylogenetic analysis and was displayed using the PHYLODENDRON program (see Methods). Bar, $0 \cdot 1$ changes per site. Protein designations are the same as those in Fig. 1.

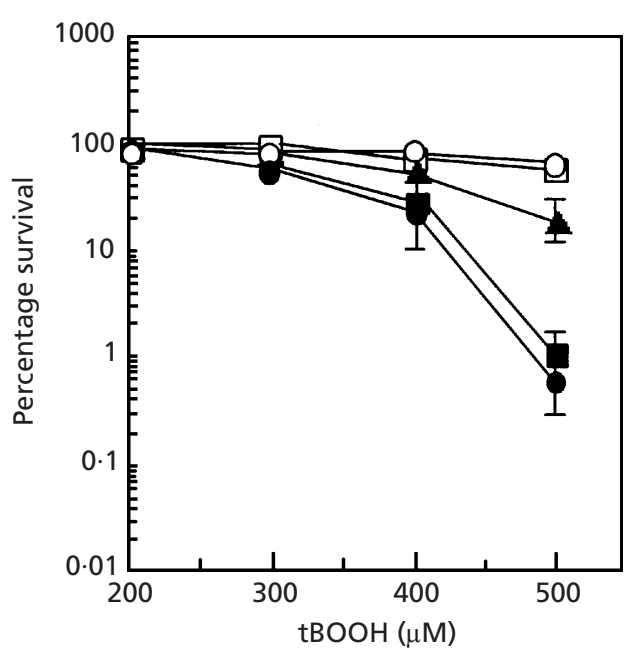

Fig. 3. Plating efficiencies of $P$. aeruginosa ohr and osmC mutants in the presence of oxidants. $P$. aeruginosa PAO1 $(O)$, an ohr mutant (O), an osmC mutant ( $\square$ ), an ohr mutant harbouring pBBRohrP $(\boldsymbol{\Delta})$ and an ohr mutant harbouring pBBRosmCP ( $\boldsymbol{\square}$ ) were grown to exponential phase, serially diluted and plated on plates containing various concentrations of $\mathrm{tBOOH}$. The experiments were performed independently four times, and the error bars represent standard error of the mean. parent strain (Fig. 3). No changes in the plating efficiency in the presence of $\mathrm{H}_{2} \mathrm{O}_{2}$ or menadione for either mutant were observed (data not shown). Mutations in oxidative stress genes can lead to decreased aerobic growth rate and plating efficiency (Mongkolsuk et al., 1998b; Hassett et al., 2000). However, both mutants had the same growth rate as the parent strain in rich medium, and no deficiency in aerobic plating was detected (data not shown).

The obr phenotype can be complemented by a plasmid containing the ohr gene (pBBRohrP), but not by a plasmid carrying the osm C gene (pBBRosmCP) (Fig. 3). The $o h r$ mutant carrying pBBRohrP showed a 60 -fold increase in plating efficiency in the presence of $\mathrm{tBOOH}$ when compared with the mutant harbouring the vector alone (Fig. 3), though this level was slightly lower than the tBOOH-resistance level attained by the parent strain. In the parental strain, obr is expressed at high levels after exposure to $\mathrm{tBOOH}$ (Fig. 4); however, ohr expression in a moderate-copy-number expression vector (pBBR1MCS-4) might not be high enough to confer full protection against $\mathrm{tBOOH}$ toxicity in the ohr mutant. pBBRohrP did not raise $\mathrm{tBOOH}$ resistance in either the parental strain or the osm $C$ mutant. These findings are similar to those presented in a previous

OsBb is from Bordetella bronchiseptica (Sanger518 bbronchi contig2522)*; OsEc is from Escherichia coli (X57433); OsTf is from Thiobacillus ferrooxidans (TIGR tferroxidans4156)*. Asterisks indicate data from unfinished genome sequences. The conserved regions found in either Ohr homologues (Oh regions) or OsmC homologues (Os regions) are shown by regions of black shading with white lettering. Grey shading with black lettering indicates identical amino acid residues found in both Ohr and OsmC (15 out of 26 sequences). $\boldsymbol{\nabla}$. Highly conserved C residues. The numbers at the ends of each line on the right-hand side refer to the numbers of amino acid residues. 

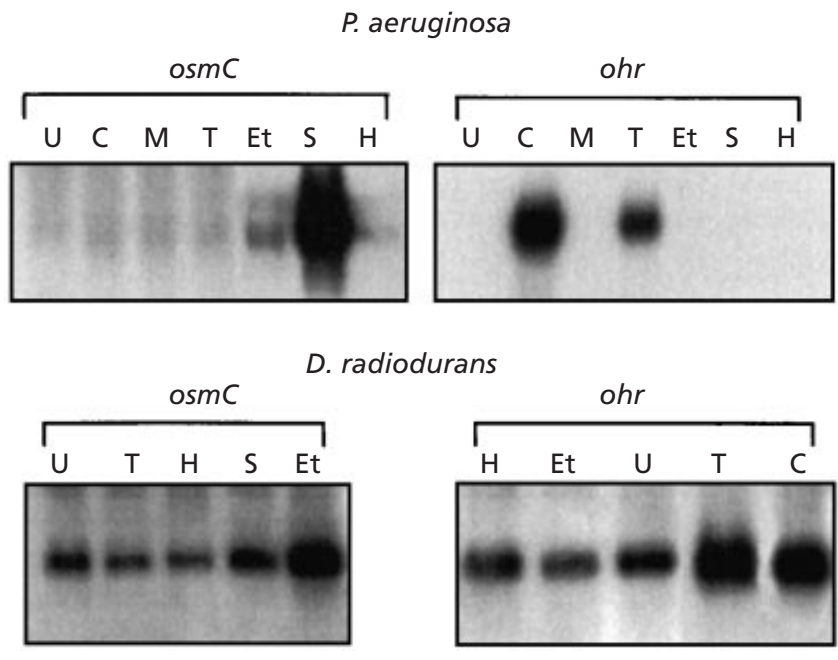

Fig. 4. Expression analysis of ohr and osmC in response to stresses in $D$. radiodurans and $P$. aeruginosa. $P$. aeruginosa and $D$. radiodurans cultures were grown and were either left untreated $(U)$ or treated with oxidants (C, cumene hydroperoxide; $\mathrm{H}_{1} \mathrm{H}_{2} \mathrm{O}_{2} ; \mathrm{M}$, menadione; $\mathrm{T}$, $\mathrm{tBOOH}$ ) or subjected to osmotic stress ( $\mathrm{S}$, salt) and ethanol stress (Et) as described in Methods. RNA isolation, gel electrophoresis, blotting and hybridization were as described in Methods. Northern blots were probed with radioactively labelled $P$. aeruginosa ohr or osmC or D. radiodurans ohr or osmC probes.

report on X. campestris pv. phaseoli, in which the wildtype strain harbouring an ohr expression vector did not display increased resistance to $\mathrm{tBOOH}$ (Mongkolsuk et al., 1998a).

We have tested several parameters, including aerobic growth, response to osmotic stress, and ethanol resistance, in the $P$. aeruginosa osm $C$ mutant and found no significant changes in these parameters in comparison with the parent strain (data not shown). A similar analysis of E. coli osmC mutants failed to detect any physiological alterations (Gutierrez \& Devedjian, 1991). The distinct phenotypes of the ohr and osmC mutants, and the inability of the osm $\mathrm{C}$ gene to complement the obr mutant, support the idea that these genes play different roles in the cell.

\section{ohr and osmC homologues have different expression patterns}

X. campestris pv. phaseoli ohr has a unique expression pattern in that its expression is induced only by organic peroxide, and not by menadione or $\mathrm{H}_{2} \mathrm{O}_{2}$ (Mongkolsuk et al., 1998a). In contrast, E. coli osmC is under both growth-phase (RpoS) and osmotic-stress regulation (Bouvier et al., 1998; Gordia \& Gutierrez, 1996). This suggests that members of the ohr and osmC subfamilies may have different patterns of stress-inducible expression.

We used Northern blotting experiments to determine the expression patterns of $o b r$ and osm Chomologues in response to osmotic and oxidative stresses in $P$. aeruginosa and $D$. radiodurans bacteria, each of which has one gene from each subfamily. In both organisms, $o h r$ was strongly induced by low concentrations of organic peroxides (cumene hydroperoxide and $\mathrm{tBOOH}$ ) (Fig. 4) but not by other oxidants such as menadione (not shown for $D$. radiodurans) or $\mathrm{H}_{2} \mathrm{O}_{2}$. Neither osmotic stress (a high salt concentration) nor ethanol induced expression of the ohr homologues. In contrast, expression of $o s m C$ homologues in both bacteria was induced by ethanol, while salt stress induced osmC expression only in $P$. aeruginosa; none of the oxidants tested induced the gene expression (Fig. 4). Thus, the patterns of ohr and osm C expression in P. aeruginosa and $D$. radiodurans are consistent with the known regulation of $X$. campestris pv. phaseoli ohr (Mongkolsuk et al., 1998a) and E. coli osmC (Gutierrez \& Devedjian, 1991). The ohr and osmC mRNAs in both bacterial species were each approximately $0.7 \mathrm{~kb}$ in length, indicating that these genes are transcribed as monocistronic mRNAs. Expression of both genes is different: obr and osmC are induced by organic peroxide and osmotic stress, respectively. At present, well-characterized regulators of stress-induced gene expression such as OxyR, SoxRS and RpoS cannot account for the $o h r$ and osm C patterns of expression, implying that these genes are regulated by novel regulators.

It was noticeable that basal levels of $o h r$ and $o s m C$ from $P$. aeruginos $a$ and $D$. radiodurans varied greatly, ranging from barely detectable amounts in the former to moderately high levels in the latter. In addition, the degree of induction varied significantly between these bacteria: D. radiodurans showed a lower magnitude of induction than $P$. aeruginosa. It remains to be seen if these differences in basal level expression and degree of induction are related to the ability of each bacterium to cope with organic peroxide stress or are simply indicative of the differences between Gram-negative and Gram-positive bacteria. It is remarkable that the patterns of stress-induced expression of $\mathrm{ohr}$ and $\mathrm{osmC}$ homologues are highly conserved in a diverse range of bacteria. This suggests that both genes might have important functions.

\section{Concluding remarks}

Members of the Ohr family are widely distributed in both Gram-negative and Gram-positive bacteria. Analysis of primary structure, the physiological characterization of mutants and expression patterns show that $\mathrm{Ohr}$ and OsmC proteins belong to different, but related, subfamilies. We have shown, in $P$. aeruginosa and $X$. campestris pv. phaseoli (Mongkolsuk et al., 1998a), that mutations in ohr increase susceptibility to organic peroxides. This phenotype, coupled with the specific induction of $o h r$ by organic peroxides, suggests that ohr represents a novel organic peroxide protection system. Recent results from Ochsner et al. (2001) confirm our finding that mutation in $P$. aeruginosa obr results in 
increased organic-peroxide sensitivity. More studies are needed to discover the physiological function of OsmC. The osmotically inducible expression of the gene suggests that it could have some kind of role in the bacterial osmotic-stress response. Recently, Conter et al. (2001) reported contradictory results that E. coli osm C mutants showed increase sensitivity to $\mathrm{tBOOH}$ but not to cumene hydroperoxide.

\section{ACKNOWLEDGEMENTS}

We thank P. Bennett for editing the manuscript. The research was supported by a grant from Chulabhorn Research Institute to the Laboratory of Biotechnology, by grants to S.M. from the Thai Research Fund (BRG/10/2543), by a career-development award (RCF 01-40-005) from the NSTDA (to S.M.), and by grant NSF 9983654 to J.D.H.

\section{REFERENCES}

Alexeyev, M. F. (1999). The pKNOCK series of broad-host-range mobilizable suicide vectors for gene knockout and targeted DNA insertion into the chromosome of gram-negative bacteria. Biotechniques 26, 824-828.

Altschul, S. F., Madden, T. L., Schaffer, A. A., Zhang, J., Zhang, Z., Miller, W. \& Lipman, D. J. (1997). Gapped BLAST and PSI-BLAST : a new generation of protein database search programs. Nucleic Acids Res 25, 3389-3402.

Baillon, M. L., van Vliet, A. H., Ketley, J. M., Constantinidou, C. \& Penn, C. W. (1999). An iron-regulated alkyl hydroperoxide reductase $(\mathrm{AhpC})$ confers aerotolerance and oxidative stress resistance to the microaerophilic pathogen Campylobacter jejuni. J Bacteriol 181, 4798-4804.

Baker, C. J. \& Orlandi, E. W. (1995). Active oxygen in plant pathogenesis. Annu Rev Phytopathol 33, 299-321.

Bouvier, J., Gordia, S., Kampmann, G., Lange, R., Hengge-Aronis, R. \& Gutierrez, C. (1998). Interplay between global regulators of Escherichia coli: effect of RpoS, Lrp and H-NS on transcription of the gene osmC. Mol Microbiol 28, 971-980.

Bsat, N., Chen, L. \& Helmann, J. D. (1996). Mutation of the Bacillus subtilis alkyl hydroperoxide reductase $(a h p C F)$ operon reveals compensatory interactions among hydrogen peroxide stress genes. J Bacteriol 178, 6579-6586.

Chae, H. Z., Robison, K., Poole, L. B., Church, G., Storz, G. \& Rhee, S. G. (1994a). Cloning and sequencing of thiol-specific antioxidant from mammalian brain : alkyl hydroperoxide reductase and thiolspecific antioxidant define a large family of antioxidant enzymes. Proc Natl Acad Sci US A 91, 7017-7021.

Chae, H. Z., Uhm, T. B. \& Rhee, S. G. (1994b). Dimerization of thiol-specific antioxidant and the essential role of cysteine 47. Proc Natl Acad Sci US A 91, 7022-7026.

Conter, A., Gangneux, C., Suzanne, M. \& Gutierrez, C. (2001). Survival of Escherichia coli during long-term starvation: effects of aeration, $\mathrm{NaCl}$, and the rpoS and osm $\mathrm{C}$ gene products. Res Microbiol 152, 17-26.

Fraser, C. M., Gocayne, J. D., White, O. \& 25 other authors (1995). The minimal gene complement of Mycoplasma genitalium. Science 270, 397-403.

Gonzalez-Flecha, B. \& Demple, B. (1997). Homeostatic regulation of intracellular hydrogen peroxide concentration in aerobically growing Escherichia coli. J Bacteriol 179, 382-388.

Gordia, S. \& Gutierrez, C. (1996). Growth-phase-dependent expression of the osmotically inducible gene osmC of Escherichia coli K-12. Mol Microbiol 19, 729-736.

Gutierrez, C. \& Devedjian, J. C. (1991). Osmotic induction of gene osm C expression in Escherichia coli K12. J Mol Biol 220, 959-973.

Halliwell, B. \& Gutteridge, J. M. (1984). Oxygen toxicity, oxygen radicals, transition metals and disease. Biochem J 219, 1-14.

Hassett, D. J., Alsabbagh, E., Parvatiyar, K., Howell, M. L., Wilmott, R. W. \& Ochsner, U. A. (2000). A protease-resistant catalase, KatA, released upon cell lysis during stationary phase is essential for aerobic survival of a Pseudomonas aeruginosa oxyR mutant at low cell densities. J Bacteriol 182, 4557-4563.

Hillas, P. J., del Alba, F. S., Oyarzabal, J., Wilks, A. \& Ortiz De Montellano, P. R. (2000). The AhpC and AhpD antioxidant defense system of Mycobacterium tuberculosis. J Biol Chem 275, 18801-18809.

Koonin, E. V., Arvind, L. \& Galperin, M. Y. (2000). A comparativegenomic view of the microbial stress response. In Bacterial Stress Response, pp. 417-444. Edited by G. Storz \& R. Hengge-Aronis. Washington, DC: American Society for Microbiology.

Kovach, M. E., Phillips, R. W., Elzer, P. H., Roop, R. M., II \& Peterson, K. M. (1994). pBBR1MCS : a broad-host-range cloning vector. Biotechniques 16, 800-802.

Levine, A., Tenhaken, R., Dixon, R. \& Lamb, C. (1994). $\mathrm{H}_{2} \mathrm{O}_{2}$ from the oxidative burst orchestrates the plant hypersensitive disease resistance response. Cell 79, 583-593.

Lim, Y. S., Cha, M. K., Kim, H. K. \& Kim, I. H. (1994). The thiolspecific antioxidant protein from human brain: gene cloning and analysis of conserved cysteine regions. Gene 140, 279-284.

Loprasert, S., Vattanaviboon, P., Praituan, W., Chamnongpol, S. \& Mongkolsuk, S. (1996). Regulation of the oxidative stress protective enzymes, catalase and superoxide dismutase, in Xanthomonas - a review. Gene 179, 33-37.

Loprasert, S., Atichartpongkun, S., Whangsuk, W. \& Mongkolsuk, S. (1997). Isolation and analysis of the Xanthomonas alkyl hydroperoxide reductase gene and the peroxide sensor regulator genes ahpC and ahpF-oxyR-orfX. J Bacteriol 179, 3944-3949.

Mongkolsuk, S., Loprasert, S., Whangsuk, W., Fuangthong, M. \& Atichartpongkun, S. (1997). Characterization of transcription organization and analysis of unique expression patterns of an alkyl hydroperoxide reductase $\mathrm{C}$ gene $(a h p C)$ and the peroxide regulator operon ahpF-oxyR-orfX from Xanthomonas campestris pv. phaseoli. J Bacteriol 179, 3950-3955.

Mongkolsuk, S., Praituan, W., Loprasert, S., Fuangthong, M. \& Chamnongpol, S. (1998a). Identification and characterization of a new organic hydroperoxide resistance $(o h r)$ gene with a novel pattern of oxidative stress regulation from Xanthomonas campestris pv. phaseoli. J Bacteriol 180, 2636-2643.

Mongkolsuk, S., Sukchawalit, R., Loprasert, S., Praituan, W. \& Upaichit, A. (1998b). Construction and physiological analysis of a Xanthomonas mutant to examine the role of the oxyR gene in oxidant-induced protection against peroxide killing. J Bacteriol 180, 3988-3991.

Niimura, Y., Poole, L. B. \& Massey, V. (1995). Amphibacillus xylanus NADH oxidase and Salmonella typhimurium alkylhydroperoxide reductase flavoprotein components show extremely high scavenging activity for both alkyl hydroperoxide and hydrogen peroxide in the presence of S. typhimurium alkylhydroperoxide reductase $22-\mathrm{kD}$ a protein component. J Biol Chem 270, 25645-25650.

Ochsner, U. A., Vasil, M. L., Alsabbagh, E., Parvatiyar, K. \& Hassett, D. J. (2000). Role of the Pseudomonas aeruginosa oxyRrec $G$ operon in oxidative stress defense and DNA repair: OxyR- 
dependent regulation of $k a t B-a n k B, a h p B$, and $a h p C-a h p F . J$ Bacteriol 182, 4533-4544.

Ochsner, U. A., Hassett, D. J. \& Vasil, M. L. (2001). Genetic and physiological characterization of $o h r$, encoding a protein involved in organic hydroperoxide resistance in Pseudomonas aeruginosa. J Bacteriol 183, 773-778.

Poole, L. B. (1996). Flavin-dependent alkyl hydroperoxide reductase from Salmonella typhimurium. 2. Cystine disulfides involved in catalysis of peroxide reduction. Biochemistry 35, 65-75.

Poole, L. B. \& Ellis, H. R. (1996). Flavin-dependent alkyl hydroperoxide reductase from Salmonella typhimurium. 1. Purification and enzymatic activities of overexpressed $\mathrm{AhpF}$ and $\mathrm{AhpC}$ proteins. Biochemistry 35, 56-64.

Stover, C. K., Pham, X. Q., Erwin, A. L. \& 23 other authors (2000). Complete genome sequence of Pseudomonas aeruginosa PA01, an opportunistic pathogen. Nature 406, 959-964.
Thompson, J. D., Higgins, D. G. \& Gibson, T. J. (1994). ClustaL W : improving the sensitivity of progressive multiple sequence alignment through sequence weighting, position-specific gap penalties and weight matrix choice. Nucleic Acids Res 22, 4673-4680.

Turner, E., Hager, L. J. \& Shapiro, B. M. (1988). Ovothiol replaces glutathione peroxidase as a hydrogen peroxide scavenger in sea urchin eggs. Science 242, 939-941.

Volker, U., Andersen, K. K., Antelmann, H., Devine, K. M. \& Hecker, M. (1998). One of two osm C homologs in Bacillus subtilis is part of the sigma B-dependent general stress regulon. J Bacteriol 180, 4212-4218.

White, O., Eisen, J. A., Heidelberg, J. F. \& 29 other authors (1999). Genome sequence of the radioresistant bacterium Deinococcus radiodurans $\mathrm{R} 1$. Science 286, 1571-1577.

Received 29 December 2000; revised 16 March 2001; accepted 2 April 2001. 